\title{
Imagination on the Past and Memory for the Future: Re-Establishment of the Lifeworld through Rituals Among the Glui/Gllana
}

\author{
Akira Takada and Yuriko Sugiyama
}

Whether living in cosmopolitan cities or on the outskirts of the Kalahari Desert, the global connections between people and things continue to multiply and intensify. However, globalization does not necessarily mean that people's lifeworlds have become standardized. Rather, it is becoming increasingly important to understand the differences between our lived experiences and to explore how people with diverse historical and cultural backgrounds can coexist. As Geschiere and Meyer (1998) indicate, globalization often highlights the tension between the 'global flow' of people, goods and images and a 'cultural closure' of identity. This is particularly true when a society confronts new, uncertain circumstances. The purpose of this chapter is to reconsider how members of a society facing rapid institutional and environmental changes can reorganize their lifeworld.

Since the late 199os, the Glui/Gllana, two closely related neighbouring groups of San, have faced enormous challenges caused by the implementation of a relocation policy aimed to accelerate the integration of the Glui/Gllana, a tiny minority in Botswana, into the imagined nation-state, which largely sets the socio-cultural system of the Tswana majority as the de facto standard. Rapid institutional and environmental changes forced the Glui/Gllana to reorganize social relationships that had been based on their kinship network and subsistence activities, which mainly relied on foraging wild plants and animals (Takada 2017). The two rituals analysed here - chebama for anomalous childbirth, and well-attended Christian-style funerals - were adopted and spread under these circumstances.

\section{The Chebama Ritual}

In 1961, the Bechuanaland Protectorate established the Central Kalahari Game Reserve (CKGR), which encroaches on the vast living area of the Glui/Gllana. Dr George Silberbauer, an anthropologist appointed as a 'Bushmen survey

(C) AKIRA TAKADA AND YURIKO SUGIYAMA, 2022 | DOI:10.1163/9789004471641_030 
officer', recommended the boundary to allow the Glui/Gllana to maintain their traditional pattern of subsistence (Silberbauer 1965: 132-8). Since the 197os, however, the Botswana government's modernization and resettlement policies have greatly affected the Glui/Gllana and, in 1997, the government relocated most of them to a settlement outside the game reserve. Soon, a ritual known as chebama, which is thought to treat the effects of anomalous childbirth, became widely practised in the new settlement, which local people call Kx'oensakene (literally 'looking for a life').

Chebama refers to both the ritual itself and the symptoms or effects of an anomalous childbirth. The symptoms of chebama are similar to those of an affliction called thibamo, which became prevalent among the Tswana in the 1930 s and 1940s (Livingston 2005). Livingston (2005) argued that thibamo emerged as a term to describe a constellation of symptoms, such as a breech birth, a persistent bloody cough and acute malnutrition in the baby and/or parents. The symptoms increased when sexual restrictions in the context of migrant labour were relaxed. Concepts relevant to biomedicine (such as disease transmission through human fluids) combined with those of Tswana medicine led to thibamo being associated with tuberculosis (тв).

According to our interviewees, the therapist who performed most of the chebama rituals in Kx'oensakene between 1997 and 2000, had learnt them from relatives who had close relationships with the neighbouring Kgalagadi people, so the chebama ritual might well have emerged from knowledge and skills associated with thibamo. Imamura (2010: 172) confirmed that "many of the rituals that the Glui/Gllana perform are influenced by the Kgalagadi people." However, it should be noted that the ritualistic aspects of thibamo are poorly documented. Also, although the traditional Tswana birth attendants are still familiar with the symptoms of thibamo and the customary medicines used to treat them, they perform few thibamo rituals. So, even if both afflictions (and treatments) share similarities, it is difficult to pinpoint their exact relationship.

The Glui/Gllana perform the chebama ritual following the diagnosis of an anomalous childbirth, which they believe can cause chest disease in the parents and/or child after birth (Imamura 2010: 178-9). As in reports of thibamo among the Tswana (Anderson and Staugård 1986), the Glui/Gllana say that if a baby is born facing the ground, it might mean it has chebama, which is curious because Glui/Gllana women usually deliver their babies in a squatting position at home. In addition, people sometimes gave an ex post diagnosis of chebama to children born at the clinic, where few witnesses see the actual birth. People around the baby (for example, the family and neighbours) also debated whether the parents had lived an inappropriate life, such as engaging in extramarital sexual intercourse. So, although Tswana customary expressions 
of breech birth are also prevalent among the Glui/Gllana people, they actually diagnose chebama by considering other factors as well. These will be discussed below.

One chebama ritual proceeded as follows (interviews and field observations). After a diagnosis of chebama, the parents asked the therapist to perform the necessary treatment (in the local expression, 'do chebama' or 'do chebama treatment'). The therapist collected several medicinal plants, including $n \neq u ̈ \iota$ kỗ (Heliotropium ciliatum), !áríbè (Otoputera burchellii), g|árì iú(Hermbstaedtia linearis), and g!òó $\mid$ òa (Cassia biensis), and visited the family's hut with his wife/ assistant. Inside the hut, the assistant made small incisions in the mother's thighs and belly with a razor blade to collect a few drops of blood. She also collected the baby's urine and made similar small incisions in the father's legs and belly to collect his blood. She then made a hole, approximately knee height, in the back wall of the hut in which the mother and baby resided. The therapist mixed the blood and urine with tinned beans - used as a substitute for nfàn-fé (Bauhinia petersiana Bolle sub sp. serpae) - and the ashes of medicinal plants. From outside the hut, the father placed his legs through the hole the assistant had made; and from inside the hut the mother did the same so that her legs came into contact with his, and the medicine was rubbed into the incisions on their thighs and belly. The father then removed his legs from the hole and entered the hut. Subsequently, the father, mother, and their kin consumed the medicine. The baby would regularly be given similar medicine, made only of tinned beans and the ashes of medicinal plants, until able to sit unassisted (Takada 2017).

As we understand it, the chebama ritual contains several body metaphors. The hut and hole represent the womb and vulva respectively. The father symbolizes the penis, while the mother and baby together represent the foetus. Furthermore, placement of the father's legs in the hole signifies sexual intercourse (people believe that the semen supplies nutrition to the foetus). Consumption of the medicine is analogous to providing purified semen or nutrition to the foetus and beginning to sit unaided is analogous to the separation of the unity of mother and child and the 'social birth' of the infant as a separate individual.

Imamura (2010) argued that Glui/Gllana rituals reflect their cosmology: all living things are filled with, and linked by, fluids (the blood, urine, sweat, and semen) that are the source of energy. If inappropriate social relationships contaminate these fluids, they need to be purified through ritual action. The importance of an appropriate flow of human fluids (one that keeps them moving smoothly) is also emphasized among other groups of San (Low 2008).

A number of demographic and socioeconomic factors influenced the frequency of chebama practices, with individuals who seemed well-adapted to the 
settled life tending to receive them more frequently. For example, families of children born with chebama tended to have more goats, donkeys, horses, and bigger huts with fences, all of which are indicative of a settled life. Families of children born without chebama, by contrast, tended to have more hunting dogs and smaller huts without fences, thus suggesting a foraging lifestyle. Moreover, the chebama was practised more frequently in the densely populated parts of the settlement (Takada 2017).

These findings suggest that chebama is associated with how Glui/Gllana people imagine inappropriate social relationships - for example, extramarital sex spreads STDS, and the disproportionate appropriation of valuable resources is an affront to their egalitarian ethics. Hence, the prevalence of chebama should be understood not as a sign of increasing instances of anomalous childbirth but as a marker of broader discord, of blocked flows in the Glui/Gllana people's social relationships in the face of drastic institutional and environmental changes in the form of government-led residential plot allocations, the promotion of livestock herding, and a decline in hunting and gathering activities.

\section{Emergence of 'Funeral Culture'}

The spread of chebama characterized the beginning of the Glui/Gllana life cycle (childbirth) in Kx'oensakene. Relocation, sedentarization, and the Kalahari drought also affected the end of the Glui/Gllana life cycle. Traditionally, death had been acknowledged by a simple burial (Tanaka 1980). If the family had insufficient time to dig a grave, they buried the corpse in the burrow of a large animal (for example an aardvark). In all cases, the bereaved used a wooden plate or digging stick to mark the gravesite. They also placed acacia tree branches on the grave to discourage carnivores from digging up and eating the corpse. Within a few weeks of the burial, the group would break down the camp and moved to a different location.

Contemporary Glui/Gllana funerals in Kx'oensakene largely resemble the Christian-style functions adopted by the Tswana (Amanze 2002). Interviews and observations show that there were six churches in Kx'oensakene in 2016, but that church attendance is low: only about 50 of approximately 1500 residents actually belong to a church and most of them are economically affluent. However, this small group of members plays a leading role in funerals, in which many people, not just members of the church, participate.

When a person dies in Kx'oensakene, the administrative office transports the corpse to a mortuary in a nearby town. The next day, the bereaved gather at the hut where the funeral will take place. A vigil, locally known as a 'memorial 
service', is held on a weekday evening, led by a few core members of the church. The deceased's relatives and friends attend the service to share endearing memories and sing popular hymns.

The day before the funeral, the deceased's relatives and friends gather in the graveyard to discuss where to locate the grave. Since kinship considerations and the spacing of the plots between the deceased have to be taken into account, the configuration of tombs in the graveyard needs to reflect these social relationships.

Funerals usually start on Friday evening and last until noon on Saturday, and people belonging to different churches also often participate in them. The bereaved bring the coffin to the hut. The prices of coffins vary from free to gooo pula (approximately $\$ 780$ ). The relatives and friends of the deceased express their condolences and spend the entire night singing popular hymns around a fire and then, at dawn, the coffin's window is opened to enable the mourners to view the deceased's face (Sugiyama 2017).

Afterwards, everybody proceeds to the graveyard on the outskirts of the residential area. As of 2016, about half the graveyard had been filled with approximately 250 graves. As with the coffins, several different types of tombs are available for purchase in town at different prices, from where the bereaved transport them to the graveyard in Kx'oensakene. Hence, as Golomski (2018) pointed out about funerals in Swaziland, the coffins and tombs are testaments to "how the deceased was well cared for in life" (Golomski 2018: 129) by the bereaved. With increased resources available to the bereaved, this 'funeral culture' made up of the new funereal forms and practices that emerged alongside other drastic social changes such as the prevalence of HIV/AIDS (Golomski 2018), has become increasingly popular in Kx'oensakene.

After the interment, the funeral participants return to the hut and the bereaved are introduced to the guests. Porridge and meat are served and, when they have finished their meal, the participants leave the hut one by one. After the funeral, the deceased's close family members often move to a new residential plot within Kx'oensakene. They reported various reasons for moving, such as to live with relatives who could help them in their daily lives; to cultivate an agricultural field in a different place; or, for widows, to avoid sexual temptations from neighbouring men (Sugiyama 2017). The change of residential plot is a signal to the survivors and people around them to reconfigure their social relationships.

Glui/Gllana funerals are usually much less formal than the Tswana ones that inspire them. Long before the funeral the Tswana discuss the roles of the participants in minute detail. For example, who will read the condolences, describe their kinship relationships with the deceased, or narrate the history of care 
that the deceased received? The Glui/Gllana casually choose a few relatives or friends available at the time of the funeral to express their condolences. Family members hand copy the texts of a Tswana funeral, but replace the names and titles (for example the kinship relationships) with those who will give the condolences. However, because they often reuse titles already written in the programme, the actual relationships with the deceased do not necessarily match. People are largely indifferent to the formality and correctness of the relationships described in the programme. In addition, if a person listed in the programme does not appear at the funeral, another will fill in for them.

Tswana people believe that "burial defines the location of a person's permanent home (legae), distinct from all other places where he or she has lived" (Klaits 2010: 70). Given that Tswana people usually change their residential village several times in their lives, choosing a graveyard in a particular village means deciding on the deceased's permanent home in the afterlife. The Glui/ Gllana, by contrast, more pragmatically choose the burial site that best reflects the context of the deceased's actual social relationships from the places available in the graveyard in Kx'oensakene. These differences suggest that, although the Glui/Gllana adopted the Christian-style funeral of the Tswana, they modified it, arousing their own "artful creation of understandings of virtue and the good" (Werbner 2016: 82). By developing their own funeral culture, the Glui/ Gllana attempt to reconstruct the social meaning of each death.

\section{Re-Establishing the Lifeworld through Rituals}

As mentioned, the Glui/Gllana assume that all living things are linked by fluids that provide a source of energy. From this perspective, an individual's body is not a closed system. Rather, it is sustained by a sense of the "mutuality of being" among relatives who "participate intrinsically in each other's existence" (Sahlins 2013: iv). Accordingly, rituals are applied across these interdependent social bodies. People in intimate relationships (for example, baby and parents, deceased and bereaved, and their kin) use rituals to mend relationships in crisis. Moreover, as we interpret it, the human body and its fluids is analogous to the entire settlement along with the flow of people/things within it. In this context, rituals are autogenerative (Devisch 1993: 39) phenomena. They are analogical metaphors that operate as situated corporeal devices rather than semantically independent textual ones. Thus, they are capable of restoring the positional value of those residents considered to have blocked or disconnected the normative flow of people/things that engender the life force.

Thus, the diagnosis of chebama does not necessarily require an anomalous childbirth. Rather, it results from the blocked relationships between the 
people around the baby. People tend to attribute the inappropriate behaviour of those who appear to be well-adapted to a settled life as the cause of chebama symptoms. By engaging in the chebama ritual, they seek to remedy moral dysfunction pertaining to bodily and social relationships. Likewise, economically affluent people adopt Christian-style funerals before the practice gradually extends to the wider community in Kx'oensakene. In this process, funerals provide them with opportunities to reconfigure their social relationships.

Moreover, in the actual course of interactions, the Glui/Gllana flexibly modify these rituals in association with their own cosmology. For example, although customary expressions of anomalous childbirth are largely shared among the Glui/Gllana, Kgalagadi, and Tswana people, the use of human fluids, like blood and urine, is a distinctive feature of Glui/Gllana rituals (Imamura 2010). The Kgalagadi and Tswana, by contrast, do not usually use human fluids to cure diseases because they associate them with witchcraft, which is legally prohibited and considered dangerous (Amanze 2002). While contemporary Tswana cosmology is inseparable from Christianity (Klaits 2010), the Glui/Gllana church members mostly use the churches in Kx'oensakene as meeting places. Most Glui/Gllana residents do not believe in an afterlife, so attendance at a funeral was motivated largely by what Werbner (2018: 319) called "moral feelings of inclusive relatedness" rather than religious belief.

The pattern of such modifications is associated with their distinctive experiences of past and future. Takada (2007) argued that while the Glui/Gllana engaged in hunting, they carefully examined the traces of animals (for example, spoor, faeces, and hair) left in the environment and employed their various senses (for example, sight, hearing, smell, and touch) and rich imagination to re-enact the events that had occurred there. Moreover, their vast hunting experiences were elaborated as cultural frames of reference (for example, the habitat and habitus of particular species of animals), which were effectively evoked while tracking prey sneaking around in the environment. Subsequently, they perceived what the future should be in the temporal horizon of the landscape and tried to deploy their expectations in the course of tracking. Nuanced gestural and verbal communication among the participants in hunting activities enhances these experiences of past and future and establishes their intersubjective lived time.

Such experiences of Glui/Gllana lived time are also reflected in their practices of the chebama rituals and funerals. For example, while determining if a baby has been born with chebama, the people around the infant try to perceive whether events or actions in the parents' past might have resulted in the baby's illness. Then, by symbolically re-enacting the baby's birth, the parents, baby, and their close relatives collaboratively attempt to regain the normal flow of their vital fluids as meaningful social endowments, which re-establishes the 
orderliness of their lives. At funerals, relatives and friends recount stories from the life of the deceased, even mimicking the latter's speech and mannerisms as they dramatize each anecdote and reconsider the deceased's social relationships. Consequently, the configuration of tombs is a representation of the social relationships among the deceased. Moreover, after the funeral, the bereaved often change their place of residence to reconfigure the appropriate social distances and relationships among the remaining individuals.

The collaborative nature of these rituals strengthened their function as tools for conviviality (Illich 1973; Nyamnjoh 2015) that enabled them to unblock the flow of their vital fluids, and hence of social relationships. Illich (1973) envisioned a convivial society that would expand the range of human abilities, management, and initiative, in contrast to societies that alienate humans through modernization. Developing Illich's argument, Nyamnjoh (2015: 263) claimed that conviviality is nurtured by "recognition and provision for the fact or reality of being incomplete". That is to say, things, words, deeds, and beings are always incomplete, not because of inherent deficiencies but because of inherent potential. Moreover, "one's well-being is affected by particular places and by the persons with whom one associates there" (Klaits 2010: 119). Modernization and resettlement policies disturbed the normal flow of people/ things among the Glui/Gllana. Nevertheless, rituals worked as tools for conviviality that facilitated "negotiation between the incompleteness of the past and the present in the interest of a non-linear future" (Nyamnjoh 2015: 15). They thereby constituted the 'architectonic', which is the method for rebuilding "the feelings and meanings that a given space may evoke" (Fernandez 1982: 408) to re-establish their lifeworld, which is rooted in their interdependent self, in the settlement named 'looking for a life' (Kx'oensakene).

\section{Acknowledgements}

This work was supported by JSPS KAKENHI Grant Number 16Ho2726, and $20 \mathrm{~J} 2343 \mathrm{O}$.

\section{References}

Amanze, J. N. 2002. African traditional religions and culture in Botswana: A comprehensive textbook. Gaborone: Pula Press.

Anderson, S. and F. Staugård. 1986. Traditional midwives. Gaborone: Ipelegeng Publishers. 
Devisch, R. 1993. Weaving the threads of life: The Khita gyn-eco-logical cult among the Yaka. Chicago: University of Chicago Press.

Fernandez, J. W. 1982. Bwiti: An ethnography of the religious imagination in Africa. Princeton: Princeton University Press.

Geschiere, P. and B. Meyer. 1998. "Globalization and identity: Dialectics of flow and closure. Introduction." Development and Change, 29, 4: 601-615. DOI: 10.1111/1467 -7660.00092 .

Golomski, C. 2018. Funeral culture: AIDS, work, and cultural change in an African kingdom. Bloomington: Indiana University Press.

Illich, I. 1973. Tools for conviviality. New York: Harper \& Row.

Imamura, K. 2010. Women living in the desert: Everyday life and rituals of Kalahari hunter-gatherers (in Japanese). Tokyo: Dobutsusha.

Klaits, F. 2010. Death in a church of life: Moral passion during Botswana's time of AIDS. Berkeley: University of California Press.

Livingston, J. 2005. Debility and the moral imagination in Botswana. Bloomington: Indiana University Press.

Low, C. H. 2008. Khoisan medicine in history and practice. Cologne: Rüdiger Köppe Verlag.

Nyamnjoh, F. B. 2015. "Incompleteness: Frontier Africa and the currency of conviviality." Journal of Asian and African Studies, 52, 3: 253-270. DOI: 10.1177/oo21909615580867.

Sahlins, M. 2013. What kinship is-and is not. Chicago: The University of Chicago Press.

Silberbauer, G. B. 1965. Report to the Government of Bechuanaland on the Bushman Survey. Gaberones (Gaborone): Bechuanaland Government.

Sugiyama, Y. 2017. Reorganization of San society seen from the changes of funeral at New Xade, Botswana: Responses to the death and changes of life. Pre-doctoral thesis, the Graduate School of Asian and African Area Studies, Kyoto University (in Japanese).

Tanaka, J. 1980. The San: Hunter-gatherers of the Kalahari, a study in ecological anthropology. Tokyo: University of Tokyo Press.

Takada, A. 2007. "Beyond the speech: Navigation practices of the Central Kalahari San." In Anthropology of living field: Process of cognition, practice, and representation on land and nature, edited by K. Kawai, 141-183. Kyoto: Kyoto University Academic Press (in Japanese).

Takada, A. 2017. "Re-enacting birth: Resettlement policy and the ritualistic treatment of abnormal birth in Botswana." In Anthropology of giving birth / making a family: An invitation to alternatives, edited by E. Matsuoka, 185-209. Tokyo: Bensey (in Japanese).

Werbner, R. 2016. "The poetics of wisdom divination: Renewing the moral imagination." Journal of the Royal Anthropological Institute, 23: 81-102.

Werbner, R. 2018. "Botswana's ecumenical funerals in the making." Journal of Southern African Studies, 44, 2: 315-329. 